\title{
Theoretical Justification of the Dermatoglyphics Use As Basic Identification Method
}

\author{
Oleksandr Dunayev ${ }^{1}$, Igor Gunas ${ }^{2} \mathbb{D}$, Oksana Popadynets ${ }^{3} \mathbb{D}$, Ruslan Kozoviy ${ }^{*}$, \\ Elvira Kindrativ ${ }^{5}$ (D)
}

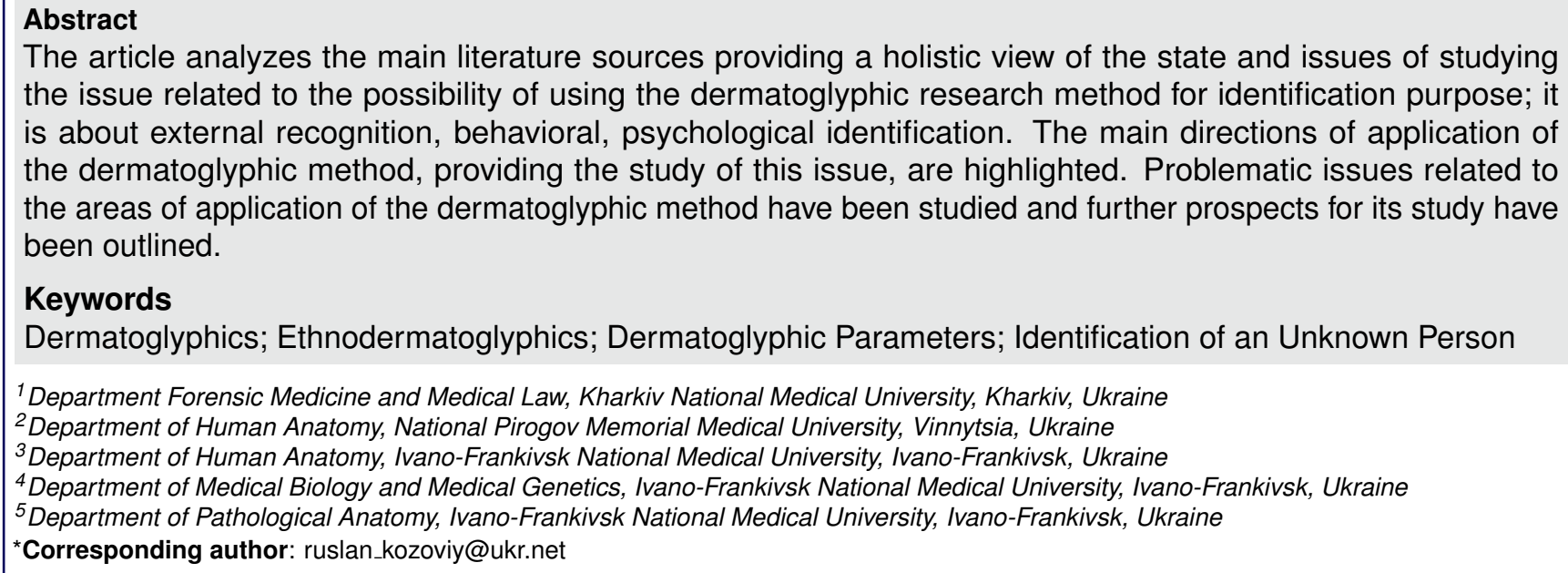

\section{Background}

Dermatoglyphs of the hands and feet are unique morphogenetic parameters exposed to both genetic and epigenetic influence, accumulating a range of valuable information, greatly expanding the possibilities of its application in practical tasks related to the identification of an unknown person, in a broad sense of the meaning (external-recognizable, behavioral, psychological identification) [1-4].

To date, dermatoglyphics of many peoples of the world has been studied or is being studied in various aspects: as a diagnostic-prognostic marker system in medicine, identification marker system in criminology, anthropological marker system of historical, evolutionary processes and genetic structure among populations [5-10]. At the same time, fragmentary literature data [11-13] do not give the possibility of the formation of a complete picture concerning the prospects of using dermatoglyphic parameters of the middle and proximal phalanges of the fingers, as a self-sufficient system of identification criteria and part of the identification dermatoglyphic complex.

\section{Discussion}

The lack of theoretical achievements and applied methodological recommendations for the integrated use of dermatoglyphic parameters of the middle and proximal phalanges of the fingers with identification purpose, attracts attention and opens new perspectives for study. Shpak LYu (2003) was one of the first researchers in anthropology studying the dermatoglyphic parameters of the distal, middle and proximal phalanges of the fingers in combination [11]. Her works represent data on gender dimorphism, bilateral and digital variability, symmetry of the skin relief of the fingers' phalanges. For the first time the regularities of inheritance of patterns of the middle and proximal phalanges were determined. Shpak LYu showed the possibility of using dermatoglyphic parameters of the middle and proximal phalanges of the fingers at the same level of the parameters of the distal phalanges, to identify the person, to establish kinship. She systematized and improved the classification of patterns of pectiniform drawing of the proximal and middle phalanges of the fingers of the hand, developed and formulated criteria according to which one may determine the parameters of family 
kinship and the possibility of establishing the child's relationship with one or both parents. The above-listed criteria open the possibility of identification of family ties both according to a set of signs of dermatoglyphics of the fingers, as well as according to one of the phalangeal systems. The researcher introduced a complete and generalized classification of patterns of the middle and proximal phalanges of the fingers.

Chistykina TA et al. have also studied the possibility of the use of dermatoglyphic parameters of the middle and proximal phalanges of the fingers for identification purposes [14]. The authors have studied the prevalence of finger patterns of the distal, middle and proximal phalanges of the fingers among the population of the Tyumen region; they have also developed dermatoglyphic diagnostic complexes.

To date, the possibility of a comprehensive study in forensic medicine and criminology of papillary patterns of the fingers in combination with anthropometric and anthroposcopic parameters of a man, with the subsequent use of the results in the prognosis of the external-discriminatory peculiarities of an unknown person, is studied sufficiently scantily.

Kozan NM has been actively studying this issue in Ukraine [12]. The author conducted a comprehensive study of dermatoglyphs of hands and feet and anthropometric and anthroposcopic parameters of representatives of different ethnic groups of Prykarpattia; the possibility to use the results obtained is highlighted (stable correlative connection between the anthropometric, anthroposcopic parameters and dermatoglyphics of hands and feet) to predict the external-discriminatory signs of human person, also co-authored an identification computer program (Dermatoglyphics for Prediction), which provided the full practical application of the developed results and algorithms.

Significant contribution Kozan NM made into Ukrainian ethnodermatoglyphics. Thus, there was performed a study of handprints of 50 people of Hutsul ethnic group and 55 women of Ukrainian nationality without genetic and dermatological diseases [15]. Significant differences between the studied groups were revealed, namely - significantly higher indices of the total frequency of ulnar loops (61.5\% vs. 19\%), significantly lower indicators of radial loops $(3.5 \%$ vs. $32 \%)$ and the total frequency of arches on both arms (5.6\% vs. 16\%) for women of Ukrainian nationality [16]. The study of fingerprints of persons belonging to the Boyko ethnic group (the study was performed with the participation of 112 men and 78 women aged 19 to 55 years) also identified specific markers for both men and women, which can then be used for their differentiation [17].

In other works, Kozan NM [18-20] studied the peculiarities of dermatoglyphic parameters of the toes in female members of the Lemko ethnic group. High frequency of tibial loops on the second and third toes of both feet and heterolateral symmetry of patterns on the type of arc and tibial loop on the first and third toes were revealed; low frequency of the loops, fibular loops, and intricate patterns on the first, fourth, and fifth toes of both feet, as well as intricate patterns, arcs, and loops on the second and third toes of both feet.

Segeda SP studied the differentiation of the Ukraine population by dermatoglyphics parameters [21]. Based on the obtained data, author analyzed the variations of the main features of this system and identified local dermatoglyphic variants (complexes) in Ukraine (northern, central and southern). Using the data obtained during the study, he identified clear dermatoglyphic parameters that are characteristic of each of the complexes and made comparisons with ethno-territorial groups living in neighboring areas. This allowed to distinguish the general dermatoglyphic parameters of Ukrainians against the background of other ethnic groups living in Europe and Asia.

In recent years, the issue of Ukrainian ethnodermatoglyphics, in particular the peculiarities of the finger patterns of somatically healthy men, is being studied by Mishalov VD et al. [22].

It should be noted that the increased interest in dermatoglyphics in recent years by forensic scientists, anthropologists, biologists gave the possibility to integrate the achievements of biology, anthropology, genetics, medicine and criminology and on this basis to solve a number of complex problems facing forensic physicians, in particular to bring to a qualitatively new level the possibility of solving traditional problems related to the diagnosis of such phenotypic features of the human being as race, age, gender, anthroscopic and anthropometric ones [23-26].

Mazur ES [27] for the first time in forensic medicine and criminology linked dermatoglyphics markers with anthropometric parameters. Namely, the study of finger and palmar dermatoglyphics using the original program, which includes the assessment of the pectiniform count in arc, curl and complex (atypical) finger samples and the study of qualitative dermatoglyphic features. The data obtained during the abovementioned study were analyzed using the method of multidimensional statistics. Taking into account the results obtainned, a number of parameters of the human constitution are formed and the statistically confirmed relationship between these parameters is shown. Also, Mazur ES has developed models for diagnosing the gender and body length, on the basis of which criteria for prognostic assessment of human physiognomic peculiarities were developed, as well as diagnostic models for predicting absolute somatometric parameters of a person were created [28].

Yarovenko VV [29] has written a research on the possibilities and benefits of using the dermatoglyphic method in forensic identification of a person in the identification of a person using dactyloscopic data, as well as in dactyloscopic registration and search of criminals.

Forensic physicians pay a lot of attention to dermatoglyphics, because of the possibility of its use in the identification of a person by establishing family kinship. In cases when dactyloscopic examination is impossible in forensic identification of a person (including unknown corpses), disputed paternity, maternity, substitution (loss, abduction) of children, determi- 
nation of family kinship of minors and people who have lost memory, one of the criteria for identification of a person is to determine his family affiliation (establishment of family kinship).

For the first time such examinations were conducted by Zvyagin VI and Tarasov IB [30]. To assess intra-familial similarity, the authors offered a comprehensive approach based on genetic analysis - in the first stage, biometric one - in the second stage and individualizing one - in the third stage of establishing family ties. In studying the heredity of dermatoglyphic traits of the feet, the researchers combined a total approach in genetic analysis and a local approach in individualization analysis, established the possibility of using individual fingers to determine intra-familial similarity. They've found that the inheritance of skin patterns of the toes has the same patterns as the fingers and do not depend on the lateral location of the patterns, the serial number of the digit and gender. It was determined that in similar phenotypes of parents the child in most cases inherits the same type on homologous digits, in addition, there is the possibility of mirror-symmetrical "transitions" of skin patterns from parents to children on a homologous or adjacent digit.

Isolation of a separate branch of dermatoglyphics - psychodermatoglyphics, was the result of numerous works devoted to the search for a connection between the peculiarity of the skin pattern and the mental sphere of human life. This field finds its application for professional selection of employees, students, pupils, detection of predisposition to mental diseases, creation of a psychological portrait for the needs of investigative bodies, etc. [31, 32].

Akbarova SN and Azimova GA [33] conducted a study to identify dermatopsychological peculiarities of persons suffering from drug addiction. Among the mental traits are such qualities as lack of kindness, inability to determine their benefits, lack of desire to engage in dialogue, poor endurance of the challenges, and so on. Specific dermatopsychological markers were also identified in the analysis of palm and fingerprints, namely - the predominance of an arc pattern on the first finger of the right hand, of the first, third, and fifth fingers of the left hand, and curls on the tenor of both the left and right palms.

Zoroastrov OM et al. [34] studied the peculiarities of the skin pattern in 231 people who were in prison for murder or grievous bodily harm. Specific features characteristic of this category of persons were revealed, namely: increase in the number of curls on the fourth finger of the right hand, on the second and third fingers of the left hand and decrease in the number of ulnar loops on the third finger of the left hand. There was also an increase in the pectiniform count on the fourth finger of the right hand and on the fifth and fourth fingers of the left hand. The obtained results will help to create the risk groups; among which it is possible to perform some preventive measures to reduce the number of serious crimes.

Efremov IS et al. [35] revealed the peculiarities of skin pattern in persons convicted of rape, namely - reducing the frequency of ulnar loops on the second finger of the right hand, increasing the number of curls and pectiniform count on the fourth finger of the right hand, reducing pectiniform score on the c-d line on the right hand, increasing the number of curls on the second up to fifth fingers of the left hand, reducing the frequency of ulnar loops on the first and fourth fingers of the left hand, reducing the number of radial loops on the second finger of the left hand, increasing the pectiniform count on the third and fourth fingers of the left hand, reducing the pectiniform account a-b on the left hand. Thus, it is possible to identify potential risk groups and carry out preventive measures [36].

\section{Conclusions}

Specific dermatoglyphic features are diagnostic markers of the formation of the main external recognition (constitutional) parameters of a person, which ensure his/her individuality, and can be confidently used for identification purposes, thus meeting the needs of forensic medicine and criminology. Also, it should be noted that dermatoglyphic parameters can also be used as specific markers in the psychological and behavioral identification of a person, providing a study of leading trends, individual style, and ways of response and behavior in life. The search for new psychodermatoglyphic connections will significantly increase the possibilities of this method and accelerate the implementation of scientific developments in the daily practice of clinicians, criminologists, investigative agencies, and other specialties.

\section{Conflict of Interest}

The authors declare that no conflicts exist.

\section{Financial Disclosure}

The authors declared no financial support.

\section{References}

[1] Mishalov VD, Gunas IV, Kryvda HF, Bachynskyi VT, Voichenko VV. Actualy questions of forensc medical dermatoglifics. Forensic-medical examination [Internet]. 2018 Mar 14;(1):17-19. Available from: https://doi.org/10.24061/2707-8728.1.2018.5

[2] Kozan NM, Cherkasov VG, Shkolnikov VS, Makarchuk IM, Marchuk IA. Diagnosis of general phenotypic characteristics of a person in the context of ICPO-Interpol requirements. World of Medicine and Biology. 2019;2(68):65-69. Available from: https://doi.org/10.26724/2079-8334-2019-2-68-65-69

[3] Bozhchenko AP. Complex diagnostics of group personality traits based on dermatoglyphics of fingers. Forensic Expertise. 2018;3:35-51. 
[4] Fedin IV, Chikun VI, Gorbunov NS, Khludneva NV. The problem of human identification. Bulletin of Forensic Medicine. 2018;1:56-60.

[5] Gutiérrez-Redomero E, Rivaldería N, AlonsoRodríguez C, Martín LM, Dipierri JE, FernándezPeire MA, et al. Are there population differences in minutiae frequencies? A comparative study of two Argentinian population samples and one Spanish sample. Forensic Science International [Internet]. 2012 Oct;222(1-3):266-276. Available from: https://doi.org/10.1016/j.forsciint.2012.07.003

[6] Hussein IA, Abdullah NF. Fingerprint Angles and Patterns in the Population of Najaf Province. Ibn Al-Haitham Journal for Pure and Applied Science. 2006;19(4):21-33. Availale from: https://www.iasj.net/iasj/article/67853

[7] Kahleel SH. Palm-print patterns in population of Diwaniyah City. Al-Qadisiyah Journal of Pure Science. 2017;17(2):25-32.

[8] Minkov T, Boichev M, Todorov V, Paraskova N, Georgiev V, et al. Dermatoglyphics characterization of Bulgarian population from some regions of southeastern Bulgaria. Journal Scientific \& Applied Research. 2015;8:47-53.

[9] Otobo TM, Tarimobo-Otobo R. Digital and palmer dermatoglyphic characteristics of the ijaw ethnic group. International Journal of Forensic Medical Investigation [Internet]. 2016 Mar 31;2(1):25. Available from: https://doi.org/10.21816/ijfmi.v2i1.18

[10] Gunas VI. Regional features of finger and palm dermatoglyphics and their connection with indicators of personality features of practically healthy men of Ukraine [thesis]. Vinnytsia, Kyiv: VNMU by MI Pirogov, NMAPE by P.L. Shupyka; 2020. 238p.

[11] Shpak LYu. Dermatoglyphics of finger phalanges (anthropological and forensic aspects) [thesis abstract]. Moscow; 2003. 25p.

[12] Kotsiubynska YZ, Kozan NM, Zelenchuk HM, Koliadenko SV, Vakar TV. Possibility of using dermatoglyphic parameters of the medium and proximal finger falanges of the hands within the requirements of dvi-interpol. World of Medicine and Biology [Internet]. 2020;16(72):074. Available from: https://doi.org/10.26724/2079-8334-2020-2-72-74-79

[13] Mishalov VD, Kostenko YY, Voichenko VV, Holubovych LL, Dunaiev OV. Perspectives of the use of dermatoglips of middle and proximal falants of the functions of the hand in Reproduction of external-recognition signs of uncertainted person. Forensic-medical examination [Internet]. 2018 Nov 22;(2):8-12. Available from: https://doi.org/10.24061/2707-8728.2.2018.2
[14] Chistikina TA, Zoroaster OM, Kolomis BE. Features of digital dermatoglyphicss of the population of the Tyumen region. Forensic medical examination. 2009;52(5):11-14.

[15] Kozan NM. Diagnosis of general phenotypic features of a person by a comprehensive study of dermatoglyphics features of the hand and foot [thesis]. Kyiv: NMAPE by P.L. Shupyka; 2018. 418p.

[16] Kozan NM. Ethno-racial features of dermatoglyphics parameters of the toes (reported 1). Forensic medical examination. 2013;2:18-21.

[17] Kozan NM. Features of dermatoglyphicss of the fingers of the female population of the Hutsul ethnic group. Bukovynian Medical Bulletin. 2013;17(3):74-76.

[18] Kozan NM. Ethno-racial features of dermatoglyphics parameters of the toes (report 2). Forensic medical examination. 2014;2:43-45.

[19] Kozan NM. Ethno-racial features of dermatoglyphics parameters of the toes (reported 3). Forensic medical examination. 2015;1:25-27.

[20] Kozan NM. Forensic identification of the ethno-territorial affiliation of an unknown person by dermatoglyphics parameters of the palms using discriminant analysis. Bulletin of Vinnytsia National Medical University. 2017;21(1):252-255.

[21] Segeda SP. Anthropological composition of the Ukrainian people: ethnogenetic aspect [thesis abstract]. Kiev; 2002. $28 \mathrm{p}$.

[22] Mishalov VD, Serebrennikova OA, Klimas LA, Gunas VI. Regional trends indicators finger dermatoglyphics among modern Ukrainians. Biomedical and Biosocial Anthropology [Internet]. 2018 Mar 29;(30):5-12. Available from: https://doi.org/10.31393/bba30-2018-01

[23] Abramova TF. Finger dermatoglyphics and physical abilities [thesis abstract]. Moscow; 2003. 51p.

[24] Bozhchenko A, Tolmachev I. A new algorithm for establishing consanguinity based on the dermatoglyphics method. Forensic medical examination. 2011;6:19-22.

[25] Bozhchenko A, Isakov V. Possibilities of diagnosing a person's gender based on the analysis of dermatoglyphics signs of fingers. Problems of expertise in medicine. 2004;4:19-23.

[26] Bozhchenko A. Possibilities of identification of significant human traits through analysis of dermatoglyphics structures of the fingers. Problems of expertise in medicine. 2004;4:42-48. 
[27] Mazur ES. Dermatoglyphics in prediction of constitutional, physical and externally identifying characteristics of a person [thesis]. Moscow; 2009. 430p.

[28] Mazur E, Dergach N. The role of medico-forensic dermatoglyphics in predicting the external identification of a person. Law. 2008;2:121-123.

[29] Yarovenko VV. The concept of dermatoglyphics examination. Law and policy. 2014;10:1610-1618.

[30] Tarasov I, Zvyagin V. Forensic aspects of dermatoglyphics of hands and feet. Forensic medical examination. 1986;2:14-16.

[31] Badikov KN. Psychodermatoglyphics innovations. Legal research. 2013;9:69-80.

[32] Badikov KN. Psychodermatoglyphics profile. Legal research. 2013;5:247-267.

[33] Akbarova SN, Azimova GA. Psychological dermatoglyphics of drug addicts. Young scientist. 2014:787-791.
[34] Zoroaster OM, Chistikin AN, Efremov IS. Dermatoglyphics features of skin patterns of persons convicted of serious crimes. Bulletin of Forensic Medicine. 2014;3(2):911.

[35] Efremov IS, Konovalov AI. Forensic dermatoglyphics. Crime prevention opportunities. Academic bulletin. 2014;2:455-457.

[36] Efremov IS, Chistikin AN, Chistikina TA. Deviant behavior and dermatoglyphics. Medical expertise and law. 2016;1:40-43.

Received: 2020-08-18

Revised: $2020-09-25$

Accepted: 2021-01-12 